aade into the still much inflamed neck. These openings were dilated with a steel director and dressing-forceps, and drainage-tubes were placed in two of them. Hot boric fomentations were continued as before and the trachea and the large wound were treated in the same manner. On March 1 st her temperature was $101 \cdot 4^{\circ}$, and the swelling of the neck had subsided considerably the discharge from all the wounds was now purulent in character and quite sweet smelling. The Symonds' tube was removed from the trachea and the whole wound was packed with gauze strips in a square of butter-muslin. Respiration was easy and quiet. She was now ordered a mixture containing 2 grains of quinine every four hours and a pint of champagne and $4 \mathrm{oz}$. of brandy in the twenty-four hours. The hot boric fomentations were continued. On the 2 nd the patient's temperature was $98.4^{\circ}$ and the discharge from the wound was sweet. The sal alembroth strips were changed three times in the twentyfour hours. The neck was much smaller in size and the tissues were soft. The tracheotomy wound was beginning to close and there were no adventitious respiratory sounds. The after history of the case was uneventful and she left the hospital early in April.

CASE 2.-A woman, aged twenty years, was seen with Dr. Hay of Plymouth on May 29th, 1898. The history was that three days previously she had consulted Dr. Hay for a *welling in the right submaxillary region. This corresponded to a carious tooth and Dr. Hay advised its removal by a dentist. The patient was not seen again until the morning of the 29th, when her neck had become much swollen on the wight side, the swelling extending to the middle line, and her general condition was much worse. The tooth bad not been removed. Dr. Hay made a median incision below the chin and ordered the application of hot linseed poultices and prescribed a mixture containing tincture of perchloride of iron every four hours. In the evening, as her condition was becoming serious, I saw her with Dr. Hay about 10 P.M. She was then sitting up in bed. She was of a -dusky purplish colour, her pulse was 120, and her temperature was $102^{\circ} \mathrm{F}$. There was a brawny inflammatory iswelling extending from the lobule of the right ear to the hyoid bone and upwards to the chin and lower jaw. The floor of the mouth was involved and the tongue was of a purplish colour and pushed up against the roof of the mouth. There was much dyspncea and -speech was impossible. Chloroform was cautiously given and I first deepened the incision below the chin -opening up the subfascial tissues after Hilton's method. Another curved incision was then made in the right submaxillary region and the deep parts were opened up in a similar manner. From both the wounds dark blood and a aittle dark-coloured pus exuded. An attempt was then made to extract the carious tooth but it caused such dyspnoea that it was abandoned. The hot poultices were reapplied. On the 30th the patient was somewhat better. The pulse was 110 and the temperature was $101^{\circ}$. The swelling had gone down a little and she could swallow liquids. On the 31 st she had a change for the worse. She was more cyanosed and dyspncic and the left submaxillary region was swelling. As her surroundings were of a poor description and nursing was practically nil I advised her removal to the South Devon and East Cornwall Hospital. This was delayed until the following morning, June 1st, when she was admitted at 11 A.M., I saw her at midday and unexpectedly found her better. Her tongue was of a red colour and she was able to protrude it from the mouth. She could articulate and could swallow beef-tea fairly easily. The incisions on the right side were beginning to granulate but there was still much swelling on both sides of the neck. It was decided not to interfere further for the present and hot boric fomentations were ordered to be applied every hour. About 7 P.M. she became suddenly attacked with dyspncea. A little chloroform was given and I incised the left side of the neck, only dark blood flowing from the wound. Directly this was done respiration ceased. A long incision was immediately made in the middle line and was rapidly deepened, but the trachea could not be found, and after a search with the finger it was felt on the left side of the neck at the depth of the forefinger from the skin and some $2 \mathrm{in}$. from the middle line. The knife was pushed along the finger and the trachea was opened and kept open with sinus forceps, and artificial respiration was performed, but the patient failed to recover.

The symptoms in the latter case were somewhat fluctuating, but I regret that I did not perform tracheotomy earlier, before the trachea, pushed across by the swelling on the right side, had become compressed by that on the left.

Plymouth.

\section{THREE CASES OF PLAGUE IN PREGNANT WOMEN ; RECOVERY IN ALL THREE CASES.}

By B. H. F. LEUMANN, M.B. Lond., D.P.H. CANTab., CAPTAIN I.M.S.; MEDICAL OFFICER IN CHARgE OF PLAGUE WARIS, S'1. GEORG'S'S HOSPITAL, BOMBAY.

As it has been stated by competent observers that during the epidemic of plague in Hong-Kong "every pregnant woman aborted and every woman who aborted died," it may be interesting to record the three following cases which have lately been under my care in the Plague Wards at St. George's Hospital, Bombay. Of these three women two came into hospital in a pregnant condition and one aborted at the beginning of the tenth day of her illness, while the other left the hospital without any abortion having occurred. The third case aborted before admission into hospital and soon after admission was considered by Dr. Yersin to be too far advanced to be injected with his serum.

CASE 1.-The patient was a woman, aged twenty years, a young Eurasian. She had been married eight months, had had no children and no miscarriages. She was admitted to hospital at 4 P.M. on Feb. 9th, 1898, after nearly twentyfour hours' illness. With regard to her history she awoke feeling quite well on the 8th, but soon after rising suffered from severe frontal headache and malaise. At 5 P.M. she had a rigor which lasted ten minutes and was followed by cramps in the hands and feet. At 6 P.M. she vomited profusely and first noticed a "painful lump in the left groin." The vomiting and fever continued unabated all night and till admission. During December and January she had had morning sickness, but it had ceased on Jan. 28th. There had been many cases of plague in her neighbourhood. On admission she was found to be a well-nourished young woman, with a flushed face, dilated pupils, injected conjunctivæ, and anxious though dull expression of countenance. The skin was hot and dry, the temperature was $105^{\circ} \mathrm{F}$., the pulse was 130 , soft and regular, and the respirations were 40 , but quite regular. The tongue was covered in the centre with a silvery-white fur, slightly moist; the edges and tip were bright red. She lay on her back with both legs drawn slightly up and the left foot crossed over the right; her hands were extended above her head. She had scratches on both her feet. She complained of great frontal headache and cough. On examination all the abdominal and thoracic organs appeared to be healthy. Towards the inner part of the left femoral region was a mass of the size of a walnut surrounded by slight odema and extremely painful on manipulation. The skin over it was not reddened and the swelling was quite distinct from the inguinal glands, which could easily be felt but were not painful. No other glandular enlargement was detected. The urine was very acid, of specific gravity 1018, no albumin and no sugar. On the 10th she had slept fairly well but could not retain her food. The bubo had increased in size and was more painful. The temperature had fallen to $101 \cdot 2^{\circ}$, the pulse was 136 , and the respirations were 32 . She was extremely drowsy and resented being roused. In the evening her temperature reached $105.2^{\circ}$ and the vomiting was more constant. On the 11th the vomiting was not relieved at all. The cough was much less. The bowels were opened after administration of calomel ; large scybalous fæces were passed. She was very drowsy now as she had hardly slept all night. There was extension of the codema to the left inguinal glands and the bubo was much more painful. No other glandular enlargement could be felt. The temperature in the morning was $103 \cdot 8^{\circ}$ and in the evening was $102 \cdot 8^{\circ}$. Her condition continued much the same until the evening of the 12th, when she became delirious - low muttering-and continued so all night. The temperature on Feb. 12th in the morning was $103.8^{\circ}$ and in the evening was $104.2^{\circ}$. On the 13th she was extremely weak and drowsy but not unconscious. When awake she was extremely nervous and difficult to manage. She vomited frequently, mostly after partaking of milk. The bowels were constipated. The physical signs were as before. The temperature in the morning was $100 \cdot 2^{\circ}$ and in the 
evening was $105.2^{\circ}$. On the 15 th the patient-who had been delirious for two nights but the previous night was violently so, constantly trying to get out of bed-was now quiet. She complained of cough and burning pain in the chest. On examination moist rîles were audible on both sides, back and front. The abdominal organs were apparently normal. The bowels were opened daily after small and frequent doses of calomel; they were semi-solid and very offensive and yellow in colour. The pulse was 140 and dicrotic. The temperature in the morning was $103.0^{\circ}$ and in the evening was $1026^{\circ}$. Pain and distension of the abdomen began in the afternoon, but had been relieved by turpentine enema and stupes. On the 16th there was no pain in the chest. The cough was almost absent; there was no headache; she was quite conscious but extremely weak. The temperature in the morning was $102.0^{\circ}$ and in the evening $101 \cdot 8^{\circ}$. On the 17th the patient-who had slept well during the previous night-was much exhausted after vomiting her meal of broth at 8 P.M. The signs were the same as before, but the bubo was less cedematous and more painful. There was slight abdominal distension and pain. Towards evening the pains in the abdomen had increased and at 8 P.M. they were extremely severe. At 3 A.M. sudden bearing-down pains occurred and she aborted at 5 A.M. (foetus of three and a half to four months). The placenta was slightly adherent and was remored by the finger. There was slight hæmorrhage afterwards. The temperature at 8 A.M. had fallen to $994^{\circ}$ and the patient seemed quite comfortable and much relieved; she was sleeping soundly. The evening temperature was $102 \cdot 0^{\circ}$. On the 18th the vaginal discharge was free, sweet, and alkaline, and yellow in colour. (Perchloride of mercury, 1 in 2000, was used as a vaginal douche night and morning.) The patient was comfortable though her temperature had risen. The temperature in the morning was $100.8^{\circ}$ and in the evening was $102 \cdot 4^{\circ}$. On the 19 th she had slept well. The discharge was yellowish red, thick, and slightly offensive. The right eye was affected with iritis. There was no pain elsewhere except in the bubo. The temperature in the morning was $101.8^{\circ}$, and in the evening was $103.2^{\circ}$. On the 20 th the vaginal douche was used thrice daily as shreds of membrane and placenta were coming away. The pain in the bubo was very great. The patient had severe headache all day. The temperature in the morning was $101.6^{\circ}$ and in the evening was $102 \cdot 6^{\circ}$. On the 22nd the temperature had reached normal and kept fairly low. The vaginal discharge was sweet and scanty, yellowish, and thin. There was much pain in the right eye and the pupil was irregular, with surrounding chemosis of the conjunctiva. The tension of the right eye very much increased. The temperature in the morning was $99.2^{\circ}$ and in the evening was $99.2^{\circ}$. On the 23 rd a drop of pus was let out of the right eye and afforded instant relief. The bubo showed signs of commencing suppuration. The temperature in the morning was $98.4^{\circ}$ and in the evening was $98.8^{\circ}$. On the 25th the bubo opened and about 1 oz. of creamy pus rescaped. The general condition was much improved. From this date the patient continued to rally in strength; on the 25th vaginal discharge entirely ceased and though the bubo was long in healing she wa soon able to sit up in bed and take solid food. The temperature remained low and hectic in character for about two weeks and then fell to normal. The patient was discharged from the plague wards on March 12th, only slight iritis remaining to worry her.

Bacteriological examination.- - On Feb. 10th bacilli ressembling those of plague were found by puncture of the bubo and microscopical examination of the lymph exudation which escaped. A culture was made on slanting agar-agar and showed numerous colonies of plague bacilli (examined and proved both microscopically and by experiments on mice) the next and second day. On the 15th the blood was examined both microscopically and by stroke cultivations on agar-agar. No colonies of any sort were found.

Treatment consisted mainly in stimulating liquid diet and good nursing. Milk, as much as she could take, with strong beef-tea, egg-flip, \&c., formed her staple food. Thirst was relieved by ice to suck. Medicinally from the first she was put on a mixture containing 3 minims of carbolic acid, 5 minims of tincture of iodine, 2 Arachms of mucilage of gum acacia with water to $1 \frac{1}{2} \mathrm{oz}$. This was given every three hours for the first day and after that four times daily till Feb. 14th. A boric acid fomentation was kept continually on the bubo and helped greatly to relieve the pain. Whenerer the temperature rose to $104^{\circ}$ she was sponged down with weak vinegar and water and the wet pack was resorted to when it reached $105^{\circ}$. As cardiac stimulants brandy and strychnine were freely given. Digitalis proved very useful in slowing and regulating the pulse-rate. Other treatment for cough, vomiting, constipation, \&c., was purely symptomatic. To produce sleep and quiet delirium morphia and atropine given hypodermically proved far more effective than hyoscine, bromidia. (which is far too depressant for these cases), or other drugs. Tonics and oleum morrhuæ were given during convalescence.

CASE 2.-The patient was a woman, aged thirty-four years, who first came under my care and then under that of Surgeon-Colonel J. Arnott, physician in charge of St. George's Hospital, Bombay, by whose permission I publish the notes of her case. On Feb. 11th, immediately after breakfast at 10 A.M., she felt giddy and sick and took to her bed and while undressing noticed her left femoral glands to be swollen. In the afternoon fever superrened and these symptoms continuing all night she was sent to hospital and was admitted at noon on the 12th. She had no rigor or vomiting. Menstruation had not occurred for nearly three months and she considered herself pregnant. On admission she appeared to be dull, lying in a crouching attitude with her legs drawn up and her head forwards on to her chest. The skin was hot and dry; the temperature was $104 \cdot 4^{\circ} \mathrm{F}$; the pulse was 120 , soft and feeble. The tongue was furred, white in the centre, with the tip and edges irritably red (typical). The thoracic and abdominal organs were apparently healthy. In the left femoral region two glands were found enlarged to the size of a hazel-nut each and they were very tender. There was no other glandular enlargement. On the 13th the patient had slept badly and now had great frontal headache. The glands in the left femoral region remained the same. The specific gravity of the urine was 1022 ; it was very acid; there was no albumin and no sugar. The temperature in the morning was $102.4^{\circ}$ and in the evening was $1020^{\circ}$. On the 14th the patient's headache prevented her sleeping, though she was distinctly dull and drowsy. The urine was neutral and contained phosphates in large quantity. The temperature in the morning was $101.6^{\circ}$ and in the evening was $102.0^{\circ}$. On the 16 th the patient was very weak. Her face had an "earthy" hue and she looked extremely dull and drowsy. The buboes were more painful and swollen. The physical signs were the same as befcre. The temperature in the morning was $100.2^{\circ}$ and in the evening was $1026^{\circ}$. On the 17 th the temperature had reached normal and the patient said she felt much better, but her appearance and signs remained unaltered. From this date she made an uninterrupted recovery, the glands undergoing complete resolution, and she left the hospital well in a fortnight.

Treatment was practically the same for this case as for the former one, except that for the first twenty-four hours she was given the carbolic acid and iodine treatment mentioned above; but after that, when under Surgeon-Colonel Arnott's care, 15 minims of solution of chlorine in water every six hours was substituted and seemed to agree very well. Other treatment was mainly symptomatic.

No microscopical or bacteriological examination was conducted in this case, but from the clinical symptoms and the fact that she had attended on one of her servants who had suffered and died from this disease there seems to be absolutely no doubt that she suffered from a mild attack of plague in its bubonic form.

CASE 3.-The patient was a married woman, aged thirtyone years, a Eurasian, living in a very infected district. She had had two children born at full time and no miscarriages. She was admitted at 6 P.M. on March 11th after three days' illness. With regard to her history, $c n$ the evening of March 8th she had felt pain in the right groin and had detected a small swelling there. The next day she did her household work, but at 4 P.M. suddenly bad a severe rigor, which lasted nearly one hour and was followed by frequent vomiting, frontal headache and fever. At 3 P.M. on the 10th severe abdominal and bearing-down pains set in and she aborted at about 5 P.M. (fœtus three and a half months)? A Hindoo medical attendant removed the after-birth, but apparently failed to diaghose the case though aware of the existence of the painful glands above mentioned. On admission the patient was found to be a thickly-set woman, with flushed face, dull expression, dilated pupils and congested conjunctiræ. She lay on her right side with both 
Iegs well drawn up to the abdomen. The temperature was $104 \cdot 6^{\circ} \mathrm{F}$, the skin was hot and dry, the tongue was coated with a silvery white fur in the centre, the tip and edges were red and cracked; the breath was foul ; the respirations were 28 and shallow; and the pulse was 124, but of fair volume. The thoracic and abdominal organs were apparently natural. The right femoral and inguinal glands were much enlarged, though distinct from one another, and they were surrounded by considerable brawny œdema. The whole tumour measured $3 \frac{1}{2}$ in. by $4 \frac{1}{2}$ in. and was extremely tender. The skin overlying it was slightly reddened and not moveable on the surface of the swelling, but no fluctuation could be detected. The lochia were very free, light yellow and sweet. The external os admitted the little finger; the internal $c s$ was dilated to admit the finger, by which means several small bits of placenta and shreds of membrane were removed. The cavity was washed out with a 1 in 3000 perchloride of mercury solution and similar vaginal douches were ordered twice daily. On the 12th, the morning after admission, the patient was seen by Dr. Yersin, who refused to inject her as he considered her case to be hopeless. The temperature had remained high, but the lochia were sweet and the pain in the bubo was slightly less. The urine was dirty yellow, of specific gravity 1020, slightly albuminons, and neutral. On the 13th, though much improved in the morning, she became very restless towards night and at 11 P.M. complained of severe pain in both iliac regions. On examination no swelling was detected. The temperature in the morning was $102.0^{\circ}$ and in the evening was $104 \cdot 8^{\circ}$. On the 14 th there was no more pain in the abdomen, she looked much better, and the bubo was considerably enlarged in size. The temperature in the morning was $103.0^{\circ}$ and in the evening was $102.4^{\circ}$. On the 15 th, the temperature remaining high, she was given $10 \mathrm{gr}$. of antefebrin in brandy at night. This greatly relieved the headache as well as being effectual in reducing the temperature $3^{\circ} \mathrm{F}$. On the 17th the bubo was opened. Caseous pus and blood escaped. Beyond copious sweating she complained of nothing. There was no pain and no other swellings were detected. The temperature in the morning was $99.6^{\circ}$ and in the evening was $101 \cdot 0^{\circ}$. From this time the patient progressed quite favourably. On the 22 nd the incision in the bubo was considerably enlarged and two more suppurating sacs were opened. On April 1st she was discharged well.

Bacteriological examinaticns of her blood were made on March 12th and 16th, but the agar tubes remained perfectly sterile. On March 17th cultures on slanting agar were made from the caseous pus and yielded many colonies of plague bacilli and a few streptococci, which were examined microscopically.

The treatment in this case was practically the same as in Case 1 and needs no further comment.

I have to thank Dr. Bitter of Cairo and Professor Gaffky for their kindness in allowing me to work in their laboratory and for confirming the bacteriological and microscopic investigations of the above cases. I am also indebted to Assistant Surgeons Lafonde, Netscher, and Macgregor of St. George's Hospital, Bombay, for their help in observing these cases clinically.

Bombay.

Wrgan Medical Society.-A meeting of this society was held on Sept. 8th, 1898, Mr. Wm. Berry, F.R.C.S.I., President, being in the chair.-Dr. Blair read a paper on the Serum Treatment of Puerperal Septicrmia, which he illustrated with copious notes from a successful case in his own practice. The usual methods of treatment were also adopted throughout. Anti-streptococcic serum was used. The serum was best employed early in the disease and then towards evening, and in all cases collapse must be watched for and obviated. The belief was expressed that recovery from puerperal septicæmia treated with serum would be more thorough than with other methods alone.Dr. Blair said it was desirable that the serum should be of standard strength and purity so that definite results could be obtained.--In the discussion on the paper the following gentlemen took part: The President, Mr. Parker, Mr. Jones, Mr. Graham, Mr. Monks, Mr. France, and Dr. Rees and Dr. Benson.-Dr. Blair replied.-A vote of thanks to Dr. Blair for his paper was moved by Dr. Benson, seconded by Mr. Monks, and carried unanimously.

\section{Olinital allotes:}

\section{MEDICAL, SURGICAL, OBSTETRICAL, AND} THERAPEUTICAL.

\section{A NOTE ON THE OCCURRENCE OF CARTILAGINOUS AND BONY NODULES OF THE TONSILS.}

By WyatT Wingrave, M.R.C.S. Eng.,

ASSISTAXT SURGEOY AND PATHOLOGIST TO THE CENTRAL LONDON THROA' AND EAIR IIOSPITAI.

IN an article published in THE LANCET of August 13th last Dr. Hugh Walsham drew attention to the existence of cartilage and bone in the faucial tonsil and expressed the opinion that they were vestigial in origin, whilst Dr. Kanthack believed that they were due to some metaplastic process. I am quite of the view that these cartilaginous masses originate in developmental vestiges and have always considered them to be identical with the subpharyngeal cartilage of Luschka, referred to in Macalister's "Anatomy," but with regard to the bony masses in some instances I am inclined to agree with Dr. Kanthack, since they are generally multiple, being often scattered about the substance of the tonsil and they are often associated with morbid changes in that structure. Still, Dr. Walsham's example of transition proves a possible chondral origin.

My experience is that cartilaginous nodules are by no means rare in this situation. Several years ago I exhibited sections at the British Laryngological and Rhinological Association and in January last further examples at the Laryngological Society of London. ${ }^{2}$ These nodules were found accidentally during the microscopical examination of diseased tonsils-mostly chronic hypertrophy-removed from patients below twenty years of age. Dr. Walsham's were, however, associated in two instances with the more mature ages of twenty-seven and fifty years, Deichert's case being as old as seventy-seven years. As in those cases, the cartilage was hyaline and white fibrous, embedded in a dense connective tissue capsule, sometimes occurring in the fibrous "bed" and sometimes in the lymphoid pulp of the tonsil, but never in the lymph nodules or follicles. I have only found calcification in one instance and this was not truly osseous. It is interesting to note that in Dr. Walsham's cases the tonsils were atrophied and that the bony elements were in excess of the cartilaginous. There must be considerable difficulty in forming a true estimate as to the frequency in the occurrence of these " nodules," since they are generally found by accident; still I have no doubt but that a systematic search will prove them to be much commoner than is generally believed. It is not an unusual experience when operating to find considerable resistance to the guillotine quite disproportionate to the density of the tonsil tissue. This I have in several instances proved, by the aid of a pocket lens and the fingers, to be due to the presence of fibrous and cartilaginous tissue, which was confirmed by the microscope. The fact that all my cases were young sub. jects is, perhaps, sufficient explanation for their being solely cartilaginous, since in the second instance described by Dr. Walsham there was partial ossification. That these nodules may as "vestigial rests" be the possible and probable foci of neoplastic changes must not be ignored, and as they are of somewhat more than transcendental interest further research as to their frequency and association may prove valuable.

Devonshire-street, $\mathbf{w}$.

CASE OF LARGE FATTY TUMOUR.

\section{By J. A. Hamilton, M.B., C.M. Edin.,} LIEUTEYAYT, I.M.S.

As cases of very large tumours are comparatively rare nowadays the following may be of interest. I am away from books of reference at present, but $I$ do not think that

1 A Text-book of Human Anatomy, by Alexander Macalister, 1889, p. 596 . 